\title{
An Empirical study on the Perceptions of the Rural and Urban Farmers on the factors influencing the Adoption of the Digital Technologies in Agriculture Sector in the State of Telangana.
}

\author{
Mr. John Paul. M \\ Assistant Professor \\ Department of Business Management, Mahatma Gandhi University, Nalgonda. (T.S)
}

\begin{abstract}
:
The present study is an attempt to understand the perceptions of the Farmers with special references to Rural and Urban area of Residence and examine if there is any variance in their opinion towards the adoption of Digital Technologies in Agricultural Sector. The study mainly focused on five factors which are draw from the extant literature available. The constructs include Perceived Usefulness, Perceived Ease of Use, Internet Usage Efficacy of the Respondents, Social influence and their Attitude towards the adoption of the Digital Technologies. The study conducted using Five-point Likert scale collecting data from 811 respondents. The non-parametric test i.e., Mann-Whitney $U$ test is employed to examine the relationship among the Rural and Urban Farmers.
\end{abstract}

Key Words: Technology Adoption, Rural and Urban, Perceived Ease of Use, Perceived Usefulness, Attitude and Social Norms.

\section{Introduction:}

The progress of Mankind since its existence passing through various phases comprising from stone age to metal ages and to the Information Technology phase of present living, have witnessed continuous progress and towards simplifying the life style from time to time. However, the present revolution which has led the anthropological advancement is Digitisation. This new phenomenon transformed human lives and propelled the mankind in to Digital Age. Today we witness every walk of life from wakeup call rings from Digital alarm clocks to dialling calls on our mobiles and to the extent to checking blood pressures in sphygmomanometer which are Digital. Emergence of Digitalization as new tool is inevitable. Various Economies across the Globe have perceived a rapid change by augmenting new Digital Technologies and Innovations in their key Sectors and which has shown Absolute Advantage in their Economies. In certain Sectors it is claimed as the "Right to Win" and beat the competition. Agriculture sector is one which need to be focused to get such advantage to reach the benefits to the farmers who are engaged in this sector.

A farmer's decision to adopt a new technology is affected by the information gained as well as his or her cognitive level and attitude about technology. Based on Rogers' innovation diffusion theory, the five-step process by which a farmer adopts a new technology is as follows: the 
farmer gains adoption knowledge, forms an attitude about the technology, makes a decision, implements it, and confirms it. Information on the agriculture technology is diffuse, both formally and informally like influence from neighbours. A farmer's gaining of information is affected by his or her ability to access information, such as his or her social capital. A farmer's cognitive level is affected by personal and family characteristics. Additionally, adoption behaviour is both a function of dynamic technology diffusion and a psychological process from cognition to decision, which is affected by many factors. The diffusion process of Technological Innovations in Agricultural Sector is slow and has less significance.

India is a country where the majority of Individual depended on Agriculture Sector and has low productivity. The extant literature has shown that socio-economic divide which is existing among the Agrarian society and are living in rural areas. This groups of people though vast in majority depend on this sector contributes less to the economy and are deprived of fruits of Technologies when compared to other sectors, they are vulnerable. In this regard, the study has collected 811 questionnaires from the agricultural farmers across the Telangana State to analyse the perceptions of the Agricultural farmers and the factors influencing the adoption of Digital Technologies among the Rural and Urban Categories in the state of Telangana.

\section{Objectives:}

The study mainly focuses on the following objectives.

1. To Understand the Perceptions of the Farmers Attitude in adoption of Digital Technologies among the Urban and Rural Areas.

2. To analyse the Perceived Ease of Use and Perceived Usefulness of the Digital Technologies among the Rural and Urban farmers.

3. To analyse the Internet Usage efficacy of the Farmers and Social Influence in adoption of Technologies in Both Urban and Rural Areas.

\section{Hypothesis Testing:}

The study formulate Hypothesis statement based on the objectives of the study. They are;

* H01: There is no significant difference in the distribution of the construct Perceived ease of Use of Digital Technologies in Agriculture Sector among the Rural and urban farmers.

* $\mathrm{H}_{02}$ : There is no significant difference in the distribution of the construct Perceived Usefulness of Digital Technologies in Agriculture Sector among the Rural and urban farmers.

* $\mathrm{H}_{03}$ : There is no significant difference in the Attitudes of the Respondents in adoption of Digital Technologies in Agriculture Sector among the Rural and urban farmers.

* $\mathrm{H}_{04}$ : There is no significant difference among respondents with regard to Social Influence in adoption of Digital Technologies in Rural and urban area of farmers.

\section{Review of Literature:}

Michels, M et al., (2020). conducted empirical study in Germany to understand the usage of Smart phones adoption in agriculture. The study explored data from 817 farmers to analyse factors influencing smartphone adoption by German farmers. The study considered age, 
education, farm size, diversification across the regions under the analysis to determine the factors influencing smart phone adoption.

Alt, V., Isakova, S., \&Balushkina, E. (2020) of Russia analysed problems arising in Digitalisation of modern agricultural production. The article scrutinises the present state of digitalisation of agriculture and problems in digital transformation process. The study found that psychological barriers, insufficient training, inadequate digital infrastructure, lack of prediction and limiting grain production, and investment are the hindering factors for digitalisation of Agriculture.

Groher,et al.(2020) in their study found that farmers residing in mountain zone were less likely adopt precision agriculture enabled Technologies compared to farmers residing in valleys. In most of the cases the Technologies are used partially to reduce the physical workload and there need to evaluate crop or management performance to find the significance of digital technologies in supporting decision making.

Rose, D. C et al., (2020) conducted an extensive research literature review to study the Agricultural Revolution 4.0 and to implement in such a way that sustains productivity benefiting the main elements like Peoples, production and planet. The Agriculture 4.0 has social implications both positive and negative. The study mainly focused the view point of Social Sustainability of people getting in to Technological trajectories.

Padhyaya, L et al., (2018) examined factors affecting Digital divide in ICT led information delivery mechanism. The results of the analysis found that factors like Gender, social Participation, awareness, affordability and economic motivation have significant influence farmers of Nashik district and age, affordability and Income have influence on Varanasi District farmers in adopting ICT in agriculture.

Deichmann, U., Goyal, A., \& Mishra, D. (2016) explored suitability and transformation of agriculture sector in developing countries based on World bank flagship report. The Economy across the globe witnessed transformation through use of Mobile phones and the internet across the sectors and leaving no exception in Agriculture. It also obvious that technology can address to certain extent of problems in rural but not all the barriers that are faced by small scale and poorer farmers in developing countries.

\section{The Variable constructs considered for the study of Technology Adoption in Agricultural Sector:}

The following are the main constructs the study has taken by considering the various Technology Acceptance Models from the Literature for the adoption of the Digital Technologies in Agricultural Sector. 


\begin{tabular}{|l|l|l|}
\hline Variable & Definition & Source \\
\hline $\begin{array}{l}\text { Perceived } \\
\text { Usefulness }\end{array}$ & $\begin{array}{l}\text { "PU construct is the belief of individual who thinks that } \\
\text { an innovation or use of the system which results in } \\
\text { enhanced performance". }\end{array}$ & Bandura (1982) \\
\hline $\begin{array}{l}\text { Perceived } \\
\text { Ease of Use }\end{array}$ & $\begin{array}{l}\text { "PEU is the degree to which an individual believes that } \\
\text { use of an innovation or a system is free and requires less } \\
\text { effort". }\end{array}$ & Rogers (1983) \\
\hline $\begin{array}{l}\text { Internet } \\
\text { Esage }\end{array}$ & $\begin{array}{l}\text { "Internet Usage Efficacy (IUE) is the capabilities of the } \\
\text { Individuals in operating or use of Technologies specially } \\
\text { the tasks that can be accomplished using internet in } \\
\text { attaining desired set goals". }\end{array}$ & Chiu, \\
\hline $\begin{array}{l}\text { Subjective } \\
\text { Norms }\end{array}$ & $\begin{array}{l}\text { "Social Norms relates to the persons' perceptions which } \\
\text { are being influenced by his or her close associates. In } \\
\text { other words, the persons expected behaviour which his } \\
\text { closed and near once expects him to perform". }\end{array}$ & Ajzen (1975) \\
\hline Attitude & $\begin{array}{l}\text { "An attitude is an individual's disposition to respond } \\
\text { favourably or unfavourably to an object, person, } \\
\text { institution, or event, or to any other discriminable aspect } \\
\text { of the individual's world" }\end{array}$ & Fishbein(1980) \\
\hline
\end{tabular}

\section{Statistical Tools Used for the Analysis:}

The Study has used five-point rating Ordinal scale for the Questionnaire. The Population mean is difficult to measure for the sample. When tested normality of Data the results have shown non-normality. Hence, the researcher has used Non-Parametric Test for the analysis. The Non parametric tests include Mann -Whitney U Test for testing the Hypothesis to find the distribution variances among the Rural and Urban Categories in Agriculture Sector.

\section{Analysis of the Data:}

The data analysis is done for each construct individually by Using Mann-Whitney U test for the variables to examine the variances among the Rural and Urban area farmers and heir perception towards the adoption of the Digital Technologies in Agricultural Sector. The variables under the study are Perceived Usefulness, Perceived Ease of Use, Internet Usage Efficacy of the Respondents, Influence of Social Norms and Attitude of the Respondents. 
1. Testing the distribution of Perceived Ease of Use for adoption of Digital Technologies in Agriculture Sector across the Groups based on Rural and Urban residence.

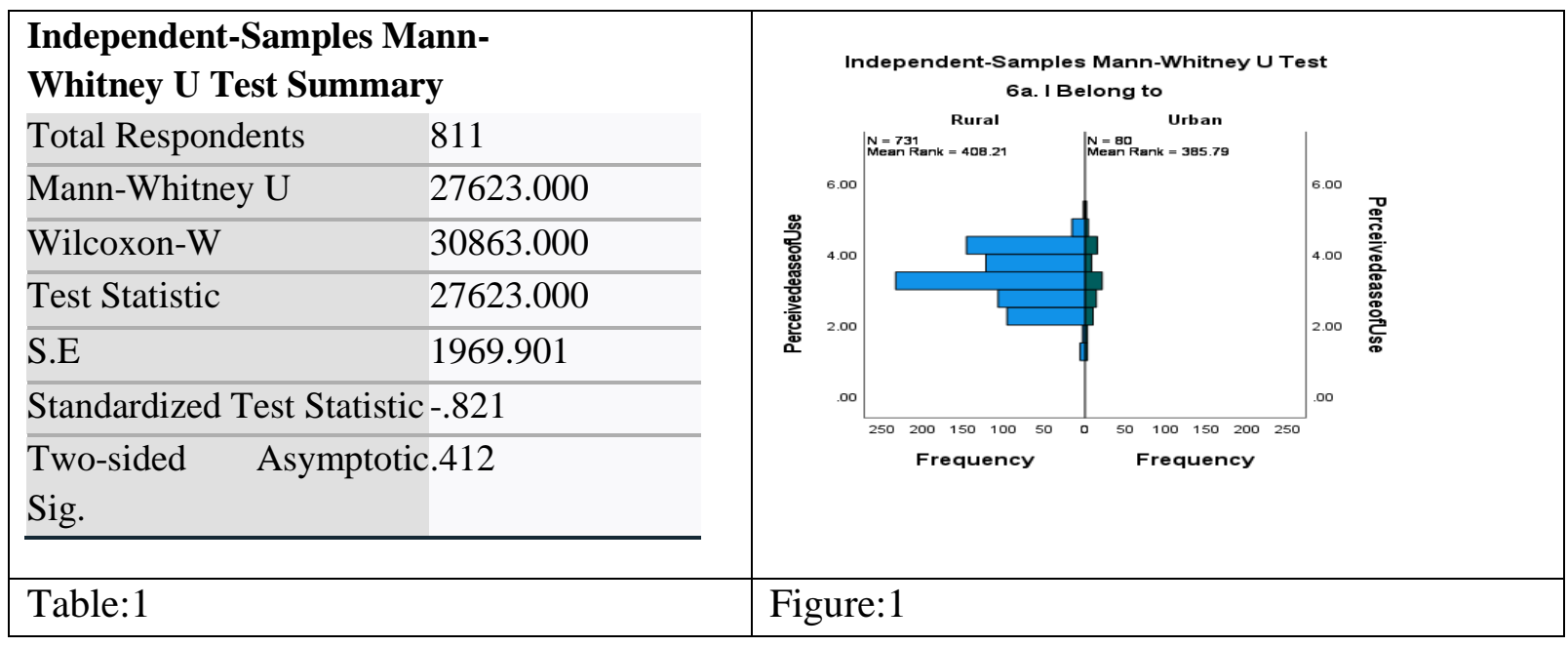

The table above is the summery of Mann-Whitney test conducted to analyse the construct Perceived Ease of Use is same across the Urban and Rural Respondents. The Mann-Whitney $\mathrm{U}$ value is 27623 and Wilcoxon-W value is 30863 . The value of test statistic is 27623 , with S.E 1969.901. The standardized Test Statistic Value is -.821 with two-sided test asymptotic significance value .412. Since, the calculated sig. value is greater than 0.05 , the Null Hypothesis is retained. It indicates that PEU of Digital technologies in agriculture sector remains same among the Rural and Urban respondents.

2. Testing the distribution of Perceived Usefulness of Digital Technologies in Agriculture Sector across the Groups based on Rural and Urban residence.

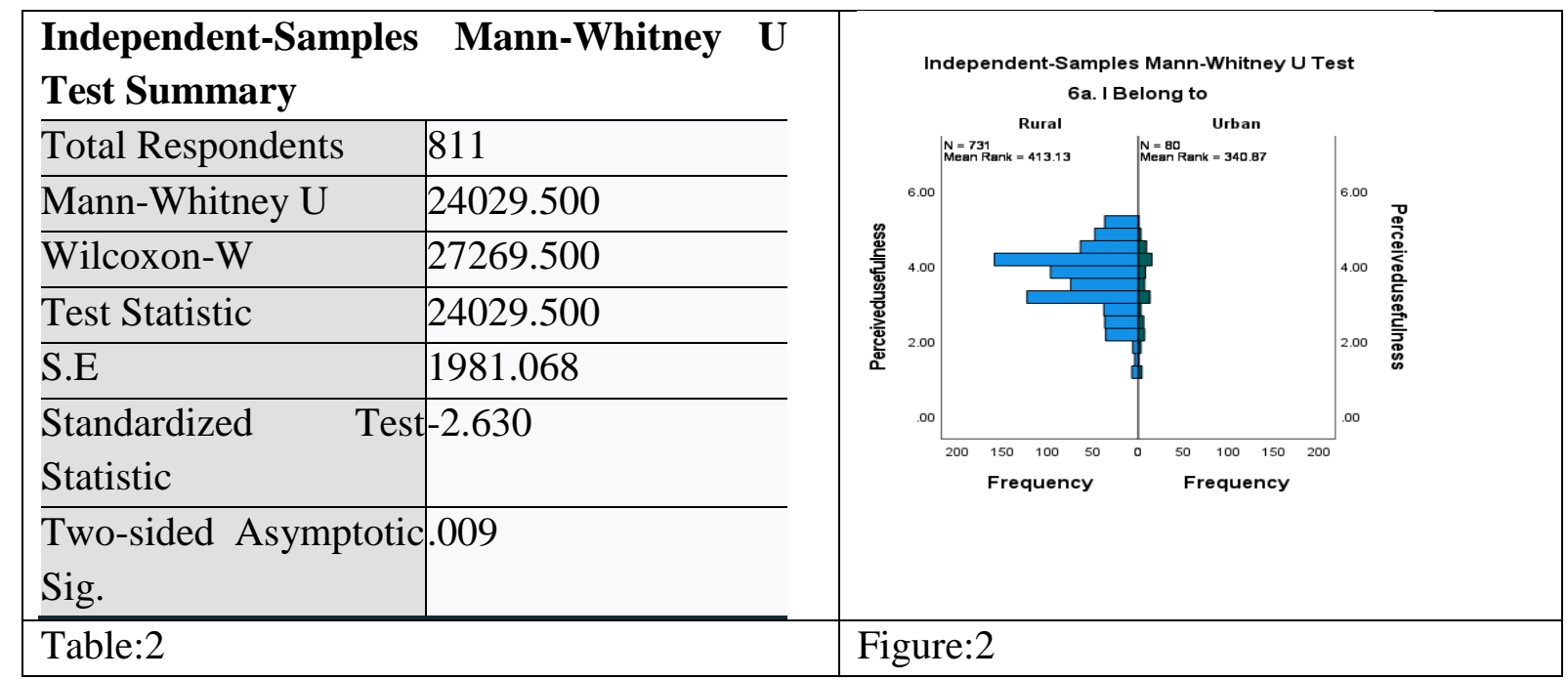

The table above is the summery of Mann-Whitney test conducted to analyse the construct Perceived Usefulness of digital technologies in agriculture is same across the Urban and Rural Respondents. The Mann-Whitney U value is 24029.5 and Wilcoxon-W value is 27269.500. The value of test statistic is 24029.500, with S.E 1981.068. The standardized Test Statistic 
Value is -2.630 with two-sided test asymptotic significance value .009 . since, the calculated sig. value is less than 0.05 , the study rejects Null Hypothesis. It indicates that Perceived Usefulness of Digital technologies in agriculture sector varies among the Rural and Urban respondents.

3. Testing the distribution of Social Influence of the Respondents in adopting the Digital Technologies in Agriculture Sector across the Groups based on Rural and Urban residence.

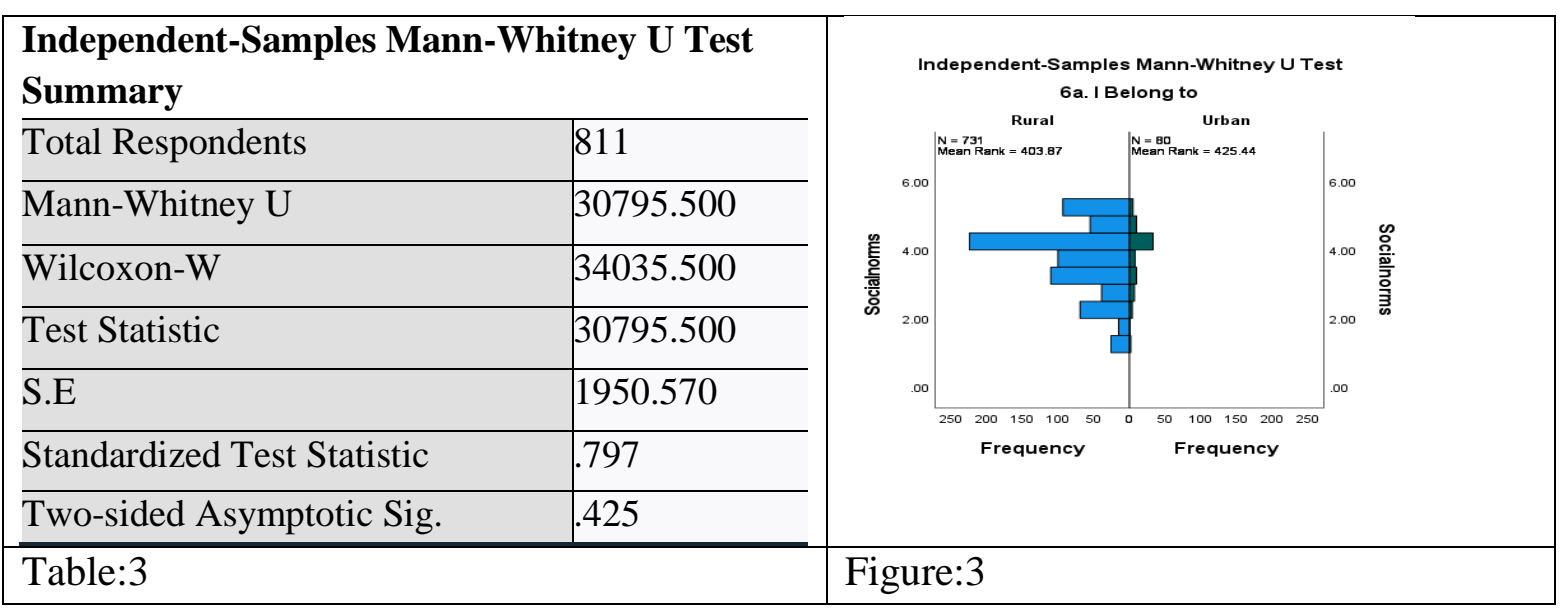

The table above is the summery of Mann-Whitney test conducted to analyse the construct Social Influence/Norms to adopt digital technologies in agriculture is same across the Urban and Rural Respondents. The Mann-Whitney U value is 30795.500 and Wilcoxon-W value is 34035.500. The value of test statistic is 30795.500, with S.E 1950.570. The standardized Test Statistic Value is .797 with two-sided test asymptotic significance value .425. Since the calculated sig. value is greater than 0.05, the Null Hypothesis is retained. It indicates that Social Influence to adopt Digital technologies in agriculture sector remains same among the Rural and Urban respondents.

4. Testing the Internet Usage Efficacy of the Respondents in Using Digital Technologies in Agriculture Sector across Groups based on Rural and Urban residence.

\begin{tabular}{|c|c|c|c|c|}
\hline \multicolumn{2}{|c|}{$\begin{array}{l}\text { Independent-Samples Mann-Whitney U Test } \\
\text { Summary }\end{array}$} & \multirow{2}{*}{\multicolumn{3}{|c|}{$\begin{array}{l}\text { Independent-Samples Mann-Whitney U Test } \\
\text { 6a. I Belong to }\end{array}$}} \\
\hline Total Respondents & 811 & & & \\
\hline Mann-Whitney U & 35180.000 & \multirow{6}{*}{ 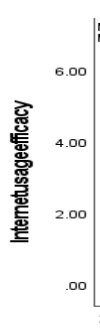 } & \multirow{5}{*}{ Nons } & \multirow{5}{*}{ 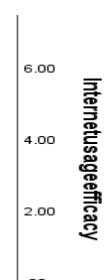 } \\
\hline Wilcoxon-W & 38420.000 & & & \\
\hline Test Statistic & 35180.000 & & & \\
\hline S.E & 1972.393 & & & \\
\hline Standardized & t 3.012 & & & \\
\hline Statistic & & & \multirow{2}{*}{\multicolumn{2}{|c|}{ 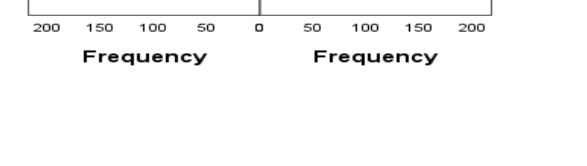 }} \\
\hline $\begin{array}{l}\text { Two-sided Asym } \\
\text { Sig. }\end{array}$ & c. 003 & & & \\
\hline \multicolumn{2}{|l|}{ Table:4 } & \multicolumn{3}{|c|}{ Figure:4 } \\
\hline
\end{tabular}


The table above is the summery of Mann-Whitney $U$ test conducted to analyse the construct Internet Usage efficacy of respondents to use digital technologies in agriculture is same across the Urban and Rural Respondents. The Mann-Whitney U value is 35180 and Wilcoxon-W value is 38420 . The value of test statistic is 35180, with S.E 1972.393. The standardized Test Statistic Value is 3.012 with two sided test asymptotic significance value .003 . since, the calculated sig. value is less than 0.05, the study rejects Null Hypothesis. It indicates that Internet usage Efficacy of the respondents varies among the Rural and Urban reside.

5. Testing the Attitudes of the Respondents in adopting the Digital Technologies in Agriculture Sector across the Rural and Urban Categories.

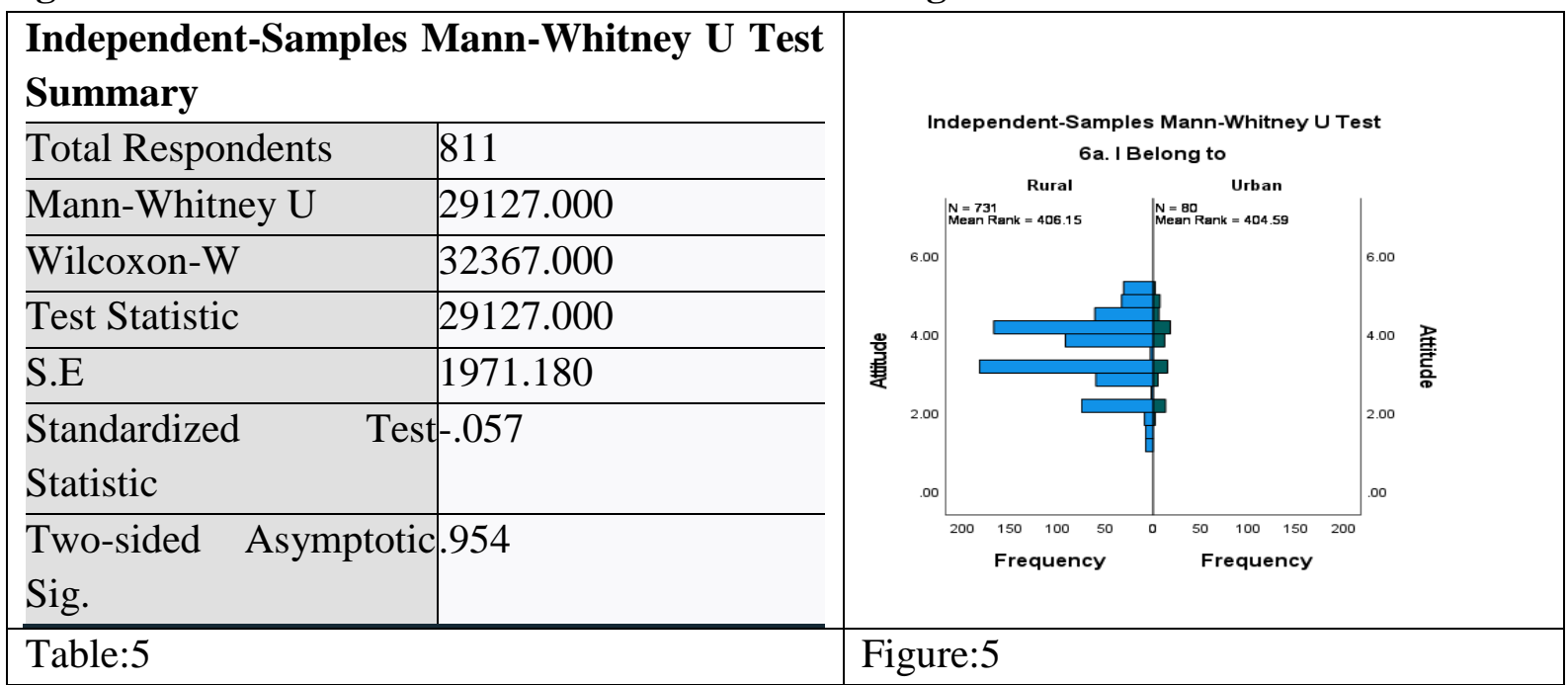

The table above is the summery of Mann-Whitney test conducted to analyse the construct Attitude towards adoption of digital technologies in agriculture is same across the Urban and Rural Respondents. The Mann-Whitney U value is 29127 and Wilcoxon-W value is 32367. The value of test statistic is 29127, with S.E 1971.180. The standardized Test Statistic Value is -.057 with two-sided test asymptotic significance value .952 . Since the calculated sig. value is greater than 0.05, the Null Hypothesis is retained. It indicates that Attitude to adopt Digital technologies in agriculture sector remains same among the Rural and Urban respondents.

\section{Summary of Testing of Hypothesis Statement:}

\begin{tabular}{|c|c|}
\hline Null Hypothesis & Sig. Decision \\
\hline $\begin{array}{l}1 \text { The perception of the respondents for the constructIndependent- } \\
\text { Perceived ease of Use in Utilising Digital Technologies inSamples M-W } \\
\text { Agriculture Sector is the same across categories of Rural Test } \\
\text { and Urban areas. }\end{array}$ & \begin{tabular}{|l|l|}
.412 & Accept \\
\end{tabular} \\
\hline $\begin{array}{l}\text { 2The Opinion of the Respondents on the construct Perceived Independent- } \\
\text { usefulness of Digital Technologies pertaining to Agriculture Samples M-W U } \\
\begin{array}{l|l}\text { is the same across categories of Rural and Urban areas. } & \text { Test }\end{array}\end{array}$ & .009 Reject. \\
\hline $\begin{array}{l}\text { 3The influence of Social norms on respondents in adopting Independent- } \\
\text { Digital Technologies in Agriculture is the same across Samples M-W U } \\
\text { categories of Rural and Urban areas. }\end{array}$ & .425 Accept. \\
\hline
\end{tabular}




\begin{tabular}{|l|l|l|l|}
\hline $\begin{array}{l}\text { 4The Internet usage efficacy of the Respondents is the same Independent- } \\
\text { across categories of Rural and Urban areas. }\end{array}$ & $\begin{array}{l}\text { Samples M-W U U } \\
\text { Test }\end{array}$ & .003 & Reject. \\
\hline $\begin{array}{l}\text { 5The respondents Attitude towards Digital Technologies in Independent- } \\
\text { Agriculture Sector is the same across categories of Rural Samples M-W U } \\
\text { and Urban areas. }\end{array}$ & $\begin{array}{l}\text { Test } \\
\text { Test }\end{array}$ & .954 & Accept. \\
\hline
\end{tabular}

Discussion of the Study:

The perceptions of the respondents pertaining to Perceived Usefulness of the Technologies in Agriculture like Usage of Technologies resulting in better farming, Saving of time through Technologies, getting quick solutions in Agriculture decision making and faster feed back mechanism are tested. Rural and urban area farmers have diffrence of opinion for the construct Perceived Usefulness. The perceptions of the respondents from the Agriculture sector for the construct Perceived Ese of Use towards Digital Technologies in Agriculture Sector among the Rural and Urban categories there is significant difference. The construct Social Norms is tested for influencing respondents in adopting the Digital Technologies. The respondents were asked whether they can adopt digital technologies if someone assists or if any one of their peer group member or family members is using similar technologies in agriculture. The Respondents have expressed that they are very much willing to adopt digital Technologies if the peer groups, relations and friend use similar technologies in Agriculture Sector. Both Urban and Rural Respondents have expressed same feeing with regard to Social Influence.

The study also tested to find Internet Usage Efficacy of the respondents to analyse the abilities of the respondents that can be a booster for encouraging the use of Digital Technologies in Agriculture. The levels of internet browsing, accessing Social networks like WhatsApp, Facebook etc., by the respondents. The study found that the Internet usage efficacy is low for the female respondents. There is significant difference among the Rural and Urban Farmers with regard to Internet Usage Efficacy. However, the study also revealed that most of the respondents are use social media networks like WhatsApp and Facebook etcin Rural area also. The respondents were asked to give their opinion whether they have a positive approach towards usage of Technologies and Idea of using them in Agricultural Decision making. the study has shown a positive response from the respondents in using information and digital Technologies in Agricultural Sector. There is no change in attitude of the Respondents when tested for adoption of Technologies in agricultural sector.

\section{Conclusion:}

The Internet connectivity is poor in remote areas and not supportive for browsing due to low band width and has frequent Network issues. The farmers are mostly illiterates and has no awareness towards the existing Digital Technologies in the field of Agriculture. Though the farmers are having the interest to adopt technologies, there requires a support mechanism like establishing communities to support each other in accessing and utilizing existing Technologies in Agriculture Sector. The study also discovered that there is inadequacy in case of service providers and are not farm specific. The nature of the Agriculture sector is heterogeneous across the state and there exists homogeneity when studies to location specific. 
In this regard the unified services across the State is not Advisable. Taking systematic training programmes the Perceived Usefulness and Perceived Ease of Use can be increased among the rural Farmers. So that they can adopt technologies and innovations in Agriculture sector and get the fruits of Digitalisation.

\section{References:}

$>$ Alt, V., Isakova, S., \&Balushkina, E. (2020). Digitalization: problems of its development in modern agricultural production. In E3S Web of Conferences (Vol. 210, p. 10001). EDP Sciences.

> Deichmann, U., Goyal, A., \& Mishra, D. (2016). Will digital technologies transform agriculture in developing countries? The World Bank.

$>$ Fishbein, M., \&Ajen, A. (1986). Intention, and Behavior: An Introduction to Theory and Research, 1975, Reading, MA: Addision-Wesley. Engel et al.

$>$ Groher, T., Heitkämper, K., Walter, A., Liebisch, F., \&Umstätter, C. (2020). Status quo of adoption of precision agriculture enabling technologies in Swiss plant production. Precision Agriculture (eingereicht).

> Jyothi, P. M. S., \& Nandan, D. (2020). Utilization of the Internet of Things in Agriculture: Possibilities and Challenges. In Soft Computing: Theories and Applications (pp. 837-848). Springer, Singapore.

$>$ Kodali, R. K., \&Sarjerao, B. S. (2017, July). A low-cost smart irrigation system using MQTT protocol. In 2017 IEEE Region 10 Symposium (TENSYMP) (pp. 1-5). IEEE.

$>$ Kosior, K. From Analogue to Digital Agriculture. Policy and Regulatory Framework for Agricultural Data Governance in the EU.

$>$ Michels, M., Fecke, W., Feil, J. H., Musshoff, O., Pigisch, J., \& Krone, S. (2020). Smartphone adoption and use in agriculture: empirical evidence from Germany. Precision Agriculture, 21(2), 403-425.Rose, D. C., Wheeler, R., Winter, M., Lobley, M., \&Chivers, C. A. (2020). Agriculture 4.0: Making it work for people, production, and the planet. Land Use Policy, 100, 104933.

$>$ Padhyaya, L., Royburman, R., Sangeetha, V., Lenin, V., Sharma, J. P., \& Dash, S. (2018). Factors affecting digital divide in ict-led agricultural information delivery: A comparative analysis. Current Advances in Agricultural Sciences (An International Journal), 10(1), 47-50.

$>$ Prathibha, S. R., Hongal, A., \& Jyothi, M. P. (2017, March). IoT based monitoring system in smart agriculture. In 2017 international conference on recent advances in electronics and communication technology (ICRAECT) (pp. 81-84). IEEE.

$>$ Rijswijk, K., Klerkx, L., \& Turner, J. A. (2018, July). Digitalisation of agricultural knowledge providers: the case of New Zealand. In European International Farm Systems Association Symposium (pp. 1-5)

$>$ S.-S. Chang, et al., Exploration of usage behavioral model construction for university library electronic resources. The Electronic Library. 33(2) (2015) 292-307.

$>\quad$ V. Venkatesh, M.G. Morris, G.B. Davis and F.D. Davis, "User acceptance of information technology: Toward a unified view”, MIS quarterly, (2003), pp. 425-478. 
$* * *$ 